\title{
The Countermeasure Analysis and Influence of Opening up Two-Child Policy to the Preschool Education in China
}

\author{
MU Xin \\ College of Mathematics and Statistics, Baicheng Normal University, Baicheng,137000,China \\ email: keaidemx@163.com
}

Keywords: Two-Child Policy, Preschool Education, Countermeasures

\begin{abstract}
With the opening of the policy of two-child, the discussion of social problems, such as shortage of labor force and aging, has been intensified. In view of the contradiction between the only one-child policy and the changing social and economic phenomena , and the great social influence brought about by the change of the policy, the scholars have put forward different views .For example, the impact, problems and countermeasures taken in preschool education have become the focus of the current debate.This paper discusses the influence of the policy of opening two children on the development of preschool education in China. It is expected that it will be of reference value for the development of preschool education, the improvement of educational working methods and the improvement of educational level.
\end{abstract}

\section{Introduction}

In order to control the total population and improve the quality of the population in the last century, China has adopted the policy of family planning, and it has long been regarded as one of the basic national policies and is implemented throughout the country. The family planning policy has played an important role in reducing the total population. However, the long-term implementation of this policy has gradually brought about the unreasonable population structure, and this trend is showing more and more unfavorable factors. If there is no change, there may be a problem of population structure inversion. The gradual increase of the number of elderly people has caused the problem of population collapse, and the impact brought by it is worth waking up. Therefore, in order to avoid the unreasonable structure of the population , the old population growth policy will be reformed , which is both a good policy and a natural law .The proportion of men and women will tend to balance in the new population policy, the nation will show a harmonious and stable development, thus gradually liberalized to fully liberalized two-child policy, is to adapt to the needs of the long-term development of society.

\section{The Impact of the Introduction of the Overall Two-Child Policy}

China is the most populous country in the world, the development of the national population policy affects the economy and society, the basic national policy of family planning for a long time, has been unable to meet the need of social and economic development. The aging of the population, the newborn reduced the inversion problem becomes more serious. In the fifth Plenary Session of the 18th CPC Central Committee of the new population policy, and points out that we should adhere to the positive response to population aging, population development strategy, encourage the two child for one couple[1]. This policy will promote the country's birth rate increase, bring new changes in the fertility rate. After the full liberalization of the two child policy is expected, will bring a new population of millions every year. The future population increment reached tens of millions. For the adjustment of our country the population structure, part of aging, has important significance to promote the development of economy and national strength. And in the promotion of the two child policy, education the impact is bigger, the scale of development The quality, the structure, and so on, will meet the challenges and opportunities. 
The Challenge of Preschool Education in Our Country after Pushing out the Two-Child Policy

The Number of School-Age Populations is the Guarantee of the Smooth Development of Educational Activities, and the Population of the School Age Determines the Number and scale of Education Development. After the implementation of the two-child policy , the demand for the quantity and scale of education in China will also be released . This is the inevitable result of the rising fertility rate. After the second child policy has been implemented , the phenomenon of the shortage of educational resources is shown to be the iron syndrome. After the implementation of the second child policy, the phenomenon of the shortage of education resources is not a short term problem .

With the Development of Social Economy, the Quality of Education Will Continue to Improve, People's Desire for High-Level Education is Unprecedented, from Learning to Learning. After the full release of the second child detection. It will become the main idea of preschool education. The increase of the school-age population means that the demand for the quality of education will increase, but if the quality of education falls, educational resources will be tight, contradictions will be planned. But some schools may re-use the large-class system of teaching. The focus of development is also on the popularization of education rather than on improving the quality of education, and the energy given to children by family education will also be dispersed[2].

Investment in Education is Often Inversely Proportional to the Growth Rate of the Population . The More Population Growth , the Social Provision of Per Capita Education Investment Will Be Reduced. According to the current level of economic development in China, the demand for talent is strong. From the population structure, the share of education investment is relatively small. So is family education investment. With one child split to two, many second-child families are more likely to face investment difficulties and overspend on education.

The layout of Preschool Education Includes Regional Distribution and Structural Divisions. The current preschool education in China of the allocation of resources, economic developed area in the eastern coastal areas is higher than that of the central and western regions and remote backward areas. Full implementation of the two child policy, will exacerbate the problem of unfair distribution of resources. And according to the survey, remote and underdeveloped areas of the two child birth rate is higher than the economic developed area and first-tier cities, but the educational resources is the quality of the focus on the latter. Contradictions emerged. And with the process of urbanization, children's education demand is also increasing, the population into the region, the shortage of education resources are not uncommon.

After the Two-Child Policy was Fully Liberalized, the Population, Especially the Number of Preschool Children, was Bound to Increase. The peak of growth will soon bring, but the quality of preschool education is also worrying. Before the implementation of this policy, the majority of families have only one child, according to the study plan and plan to construct the characteristics of only children, has formed a mature industry chain. The child was given the expected value often too high, but with the arrival of the two child policy, the expected value is reduced or even, investment will occur for the allocation, education and training institutions, will be a huge change. On education and training planning must reconsider, from preschool education investment, the change of parents the concept, characteristics of preschool children, will have to face a series of changes in turn the world upside down.

\section{An Analysis of the Development of Preschool Education in China}

Before the implementation of the comprehensive second child policy, the one-child policy and the two child policy in our country have brought about the prosperity of preschool education. 


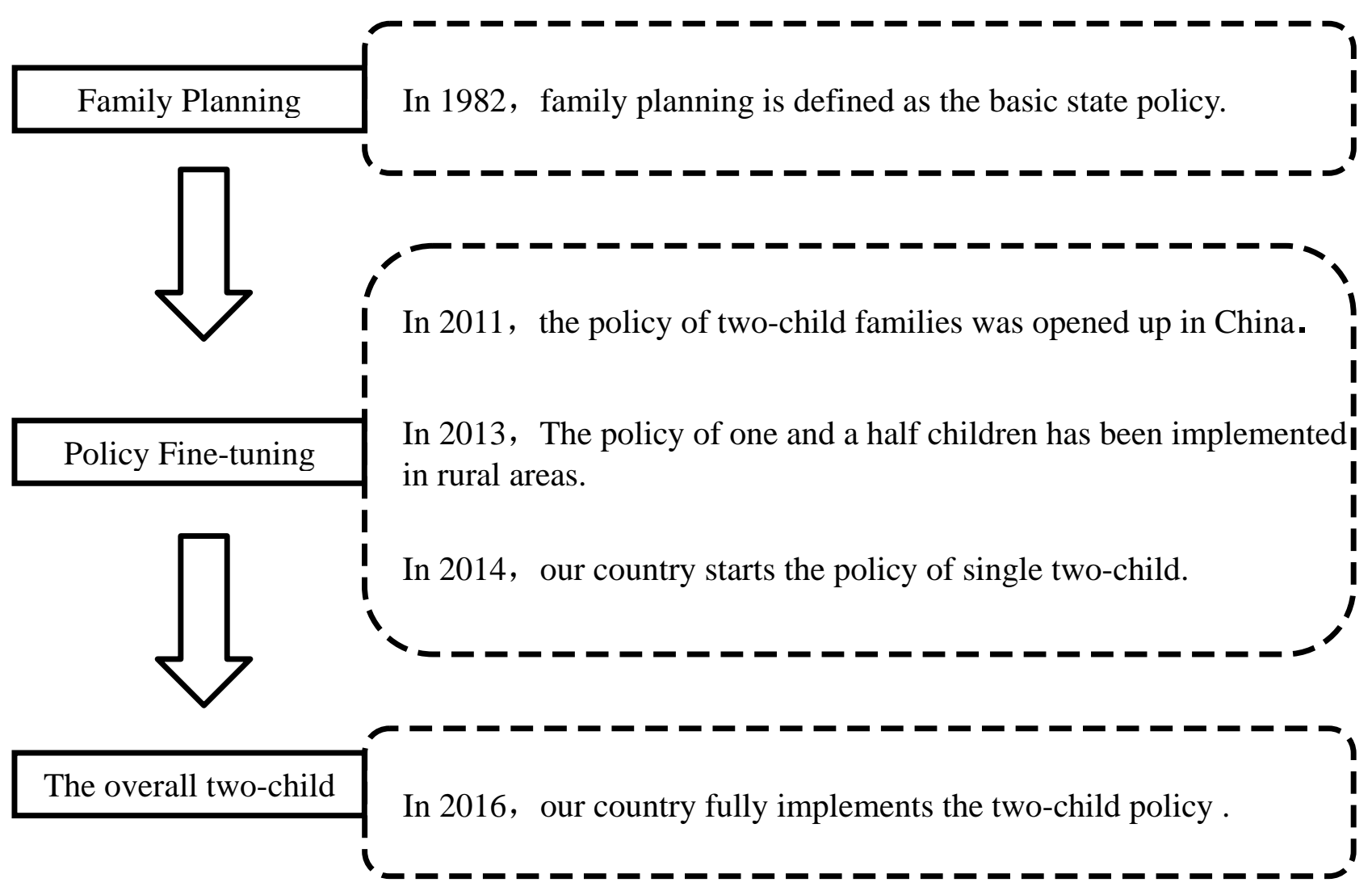

\section{The Adjustment Process of Fertility Policy in China}

With the full launch of the two child policy in our country, the natural growth rate of newborn increased year by year, can be said to reverse before China's birth rate is low, the baby boom brought preschool education and greater development opportunity. The kindergarten education is the rigid demand for families. The development of the downstream industry chain of preschool education must carry on the expansion[3]. For a long time, preschool education is an important part of the education industry and public utilities, has been getting support and attention. The related laws and regulations of preschool education are increasingly improved. For example, China's regulations on long-term education development planning and development program, aimed at many problems of preschool education policy support. Whether it is the legal level, economic development level, are admitted to preschool education in public and private legitimacy and profitability for education. The securitisation of production has also been strongly supported. The channel of school assets listing is more smoothly, preschool education has gained a lot of money, preferential policies, and social forces participating in preschool education are very enthusiastic.

The Implementation of the Two-Child Policy has Led to an Increase in the Number of Preschool Children, but there is A Shortage of Educational Resources. The construction of kindergarten can not keep up with, the quantity and quality of kindergarten teachers are difficult to satisfy. National finance has been increasing the construction of preschool education facilities, but the high level of educational resources, education talent is still scarce. Preschool education is regarded as an important part of the starting line for most parents in our country. The government pays more attention to the public kindergarten investment from a macro perspective, regardless of the treatment of teaching staff. Social status is relatively superior, by contrast, private kindergartens appear to be slightly inferior, and practitioners of education, quality and other standards can not be unified. Some preschool education institutions would rather hire old teachers. In order to obtain more practical experience, the old teachers' ability to deal with modern education can not be generalized, and the current problem of the loss of educational talents is also worthy of attention. 
According to a survey of teachers ' gaps in the preschool education phase for the two-child policy , the gap in demand for preschool education will reach millions by 2021[4].

Statistics of Preschool Teachers' Needs as of 2021 (Tens of thousands)

\begin{tabular}{cccc}
\hline Number of children in the garden & \multicolumn{2}{c}{ Demand Conditions } & Difference \\
\hline \multirow{2}{*}{5063.32} & Full-time teacher & Nursery governess & \multirow{2}{*}{300} \\
& 384.25 & 195.3 & \\
\hline
\end{tabular}

For Education, due to the Impact of Society, Family and so on, Contemporary Students Bear Too Much Pressure. Some children from birth to participate in a variety of extracurricular tutoring, various languages, various remedial studies. Filled with children's childhood, young people will recite many Tang poetry, will be a variety of add and subtract multiplication and division calculation methods, but they still yearn for happiness and freedom, and in accordance with the common sense of children of appropriate age. These children know very little. This cannot be said to be the inflexibility of preschool education in our country, but also the failure of the idea of family education.

In Order to Promote the Development of Preschool Education and Improve the Quality of Education, our government has formulated and implemented the Preschool Education Management and Other Regulatory Documents. However, the preschool education legislation level is only in the 4th level of our country's education legal system, compared with compulsory education, higher education, vocational education. In addition, the leaders of education administrative departments in some regions do not attach importance to the role of the development of preschool education in the individual growth and the development of the country as a whole. District preschool education cannot be given protection measures, and preschool education is not mentioned or even mentioned in the district work plan.

\section{Countermeasures for Preschool Education after the Full Implementation of the Two-child Policy}

Changes in Population Structure Require More Reasonable Adjustment and Planning of Educational Resources. With the increase of the number of newborns, the resources need to be expanded and increased accordingly. In the area, the planning and support of kindergarten construction should be strengthened . In particular, the input of quality public kindergartens should be increased . For the education resources, different planning and allocation should be carried out according to different stages of development, and the encouragement and encouragement mechanism should be given to the improvement of the educational structure , the construction of teachers and teachers, the promotion of teachers ' treatment, and the strengthening of preschool education team and the continuous improvement of the quality of education[5].

Government departments in charge of education management should attach importance to the development of preschool education under the new situation, increase investment in preschool education, build basic education institutions, purchase educational equipment, and train teaching personnel. Pay attention to the common development of public and private kindergartens, in line with the principle of advanced ideas, distinctive characteristics, encourage the construction of private kindergartens, and encourage social forces to participate in the construction of kindergartens, give more policies. Provide security for preschool education.

Teachers guide parents to set up scientific educational concept, change the educational concept formed under the one-child policy, from the perspective of the development of kindergarten comprehensive quality, to give all children the same input, such as children's behavior. Children's psychology and other scientific fields, parents should be educated, given theoretical guidance, so that they have the ability to practice. At the same time, increase investment in family education support policy. We should reform the system of using educational funds in a planned way, ease the pressure of funds on education and family education, put in place a diversified mechanism of education financing, give help to families and students in need, and increase the right to co-ordinate 
the funds of the places where the funds are spent. Establish the family subsidy mechanism of many children, reduce the pressure of family education.

After the two Child Policy Implementation, Education Planning and Configuration to a Reasonable Distribution from the National Scope. To narrow the differences between urban and rural areas in the West and the Middle East, do education resources, the population distribution, changes in flow were analyzed prospectively, and adjust the layout of network, improve school conditions, do all the school age population, fully play the education resources.

In the face of the increasing number of newborns, we should focus on the demand of preschool education, plan educational resources ahead of time, master the changes of population birth rate, population age structure and regional distribution, and increase the adjustment of resources. To speed up the allocation of educational resources, to meet the needs of children moving with the construction of all-round basic facilities, for schools with insufficient student resources, can absorb the floating school-age population to enter the school.

We should increase their professional and training efforts for preschool teachers, enhance treatment and encourage policies to enable outstanding teachers to meet their educational needs.

\section{Conclusion}

To sum up, the development prospect of preschool education is broad. The full implementation of the two-child policy has brought better opportunities for the development of preschool education. In the future, the direction of development is to meet the needs of preschool education of the school-age population. We should actively take measures to increase investment in education and promote the healthy and steady progress of preschool education.

\section{Acknowledgement}

In this paper, the research was sponsored by the Educational Science Project of Jilin province during “13th Five-Year Plan” in 2017 (No. GH170594) .

\section{References}

[1] LI Yin. The study on the Influence and Countermeasures of the "Fully Open the Second Child" Policy to the Preschool Major[J].Ability and Wisdom,2017,(18):30.

[2] CHEN Yugang. The Financial Planning of the second Child for families with an income of 400,000 Yuan per year[J].Financial Planner,2016,(10):68-69.

[3] WU Yali. The Opportunities and Challenges of College Students Majoring in Preschool Education in "Internet Plus" Situation[J]. Heihe Education,2017,(10):85-86.

[4] LIU Haite, JIANG Xiaopan, SHEN Pingdeng. The Influence and Countermeasures of the "Fully Open the Second Child" Policy[J].The Science Education Article Collects,2017,(27):107-109.

[5] SHEN Fucheng. The Change of Children and the Thinking and Distance of Preschool Education[J].Education Teaching Forum,2017,(26):61-62 